\title{
Piperine from the Fruits of Piper longum with Inhibitory Effect on Monoamine Oxidase and Antidepressant-Like Activity
}

\author{
Seon A Lee,,${ }^{a}$ Seong Su Hong, ${ }^{a}$ Xiang Hua Han,,${ }^{a}$ Ji Sang Hwang,,${ }^{a}$ Gab Jin OH,,${ }^{b}$ Kyong Soon Lee, ${ }^{a}$ \\ Myung Koo LeE, ${ }^{a, c}$ Bang Yeon Hwang, ${ }^{a}$ and Jai Seup Ro*,a \\ ${ }^{a}$ College of Pharmacy, Chungbuk National University; Cheongju 361-763, Korea: ${ }^{b}$ Samjin Pharm. Co. Ltd.; Hwasung \\ 445-920, Korea: and ${ }^{c}$ Research Center for Bioresource and Health, Chungbuk National University; Cheongju 361-763, \\ Korea. Received January 17, 2005; accepted March 22, 2005
}

\begin{abstract}
A bioassay-guided isolation of the ethanol extract from the fruits of Piper longum yielded a known piperidine alkaloid, piperine, as a monoamine oxidase (MAO) inhibitor. Piperine showed an inhibitory effect against MAO-A ( $\mathrm{IC}_{50}$ value: $\left.20.9 \mu_{\mathrm{M}}\right)$ and $\mathrm{MAO}-\mathrm{B}\left(\mathrm{IC}_{50}\right.$ value: $7.0 \mu_{\mathrm{M}}$ ). Kinetic analyses by a Lineweaver-Burk plot clearly indicated that piperine competitively inhibited MAO-A and MAO-B with $K_{\mathrm{i}}$ values of $19.0 \pm 0.9 \mu \mathrm{M}$ and $3.19 \pm 0.5 \mu \mathrm{M}$, respectively. The inhibition by piperine was found to be reversible by dialysis of the incubation mixture. In addition, the immobility times in the tail suspension test were significantly reduced by piperine, similar to that of the reference antidepressant fluoxetine, without accompanying changes in ambulation when assessed in an open-field. These results suggest that piperine possesses potent antidepressant-like properties that are mediated in part through the inhibition of MAO activity, and therefore represent a promising pharmacotherapeutic candidate as an antidepressant agent.
\end{abstract}

Key words Piper longum; piperine; monoamine oxidase inhibitor; antidepressant agent

Monoamine oxidase (MAO) catalyzes the oxidative deamination of monoamine neurotransmitters such as serotonin, dopamine, and norepinephrine, and appears to play important roles in several psychiatric and neurological disorders. ${ }^{1,2}$ MAO has been divided into two subtypes, MAO-A and $\mathrm{MAO}-\mathrm{B}$, on the basis of their amino acid sequence, substrate and inhibitor selectivity, and tissue distribution. ${ }^{2-4)} \mathrm{MAO}-\mathrm{A}$ inhibitors are useful in the therapy of mental disorders, mainly as antidepressants, whereas MAO-B inhibitors are expected to be useful in the therapy of Parkinson's and Alzheimer's disease. ${ }^{1,5)}$ To date, a number of MAO inhibitors such as coumarins, xanthones, and isoquinoline alkaloids have been isolated from natural products or synthesized. ${ }^{6-9)}$

Piper longum L. (Piperaceae), a slender aromatic climber, is a native of the Indo-Malayan region and grows wild in the tropical rain forests of India. The extract of the crude drug "Piperis Longi Fructus," the fruits of $P$. longum, is frequently used in folk medicine to treat bronchial trouble and is used as a carminative and analgesic. ${ }^{10,11)}$ Piperine was the first amide isolated from Piper species and was reported to display central nervous system depression, antipyretic, and anti-inflammatory activity. ${ }^{12,13)}$

Moreover, previous studies have demonstrated that piperine and its derivatives present sedative-hypnotic, tranquilizing, and muscle-relaxing actions and can intensify the depressive action of other depressants. ${ }^{14)}$ Based on the aforementioned evidence, it might be suggested that piperine could be useful for the control of CNS-related conditions, including mood disorders and moderate or mild depression states.

In the present work, we have investigated the activityguided isolation and inhibitory effect of piperine on MAO activity in mouse brain. We also investigate the antidepressant-like activity of piperine in the in vivo tail suspension test.

\section{Results and Discussion}

In our ongoing search for naturally occurring MAO in- hibitors, an ethanol extract of the fruits of $P$. longum exhibited strong inhibitory activity on mouse brain MAO. A bioassay-guided isolation of the extract yielded a known piperidine alkaloid, piperine, as an active component. The structure was identified by physicochemical and spectroscopic methods (mp, UV, IR, MS, ${ }^{1} \mathrm{H}$ - and ${ }^{13} \mathrm{C}-\mathrm{NMR}$ ) and by comparing the data obtained with those of published values (Fig. 1). ${ }^{15,16)}$

Piperine exhibited $38.0 \%$ inhibition of MAO activity at $8 \mu \mathrm{M}$, with an $\mathrm{IC}_{50}$ value of $11.1 \mu \mathrm{M}$, which is comparable to iproniazid as a positive control (Table 1). According to the kinetic properties of MAO from the mouse brain, the values of $K_{\mathrm{m}}$ and $V_{\max }$ by using kynuramine were $72.2 \pm 5.60 \mu \mathrm{M}$ and $3.97 \pm 0.18 \mathrm{nmol} / \mathrm{min} / \mathrm{mg}$ protein, respectively $(n=3)$ (data not shown).

In order to verify the selectivity of the MAO activity, $l$-deprenyl-pretreated MAO preparation was used for the measurement of MAO-A activity, whereas a clorgyline-pretreated preparation was used for MAO-B. This result indicated that

Table 1. Inhibitory Effects of Piperine on MAO in Mouse Brain

\begin{tabular}{lrccc}
\hline \hline & $\begin{array}{c}\text { Concentration } \\
(\mu \mathrm{M})\end{array}$ & \multicolumn{2}{c}{$\begin{array}{c}\mathrm{MAO} \text { activity }(\% \text { of control) } \\
(\mathrm{nmol} / \mathrm{min} / \mathrm{mg} \text { protein })\end{array}$} & $\begin{array}{c}\mathrm{IC}_{50} \\
(\mu \mathrm{M})\end{array}$ \\
\hline Control & & $2.305 \pm 0.088$ & $(100.0)$ & \\
Iproniazid & 10 & $1.106 \pm 0.020$ & $(57.6)$ & 12.9 \\
Piperine & 2 & $2.047 \pm 0.013$ & $(88.8)^{*}$ & 11.1 \\
& 8 & $1.429 \pm 0.005$ & $(62.0)^{* *}$ & \\
& 24 & $0.832 \pm 0.005$ & $(36.1)^{* * *}$ & \\
& 36 & $0.553 \pm 0.009$ & $(24.0)^{* * *}$ &
\end{tabular}

The data represent the mean \pm S.E.M. of three independent experiments performed in triplicate. Significantly different from the control value: $* p<0.05 ; * * p<0.01$; $* * * p<0.001$ (Student's $t$-test).

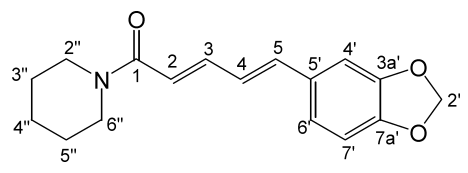

Fig. 1. Chemical Structure of Piperine 
Table 2. Inhibitory Effects of Piperine on MAO-A and MAO-B in Mouse Brain

\begin{tabular}{|c|c|c|c|c|}
\hline \multirow[b]{2}{*}{ Control } & \multirow[t]{2}{*}{$\begin{array}{l}\text { Concentration } \\
(\mu \mathrm{M})\end{array}$} & \multicolumn{2}{|c|}{$\begin{array}{l}\text { MAO activity ( } \% \text { of control) } \\
(\mathrm{nmol} / \mathrm{min} / \mathrm{mg} \text { protein })\end{array}$} & \multirow[t]{2}{*}{$\begin{array}{l}\mathrm{IC}_{50} \\
(\mu \mathrm{M})\end{array}$} \\
\hline & & $2.305 \pm 0.132$ & $(100.0)$ & \\
\hline MAO-A (deprenyl-treated) & & & & 20.9 \\
\hline Control+deprenyl & & $0.863 \pm 0.030$ & $(100.0)$ & \\
\hline \multirow{4}{*}{ Piperine } & 4 & $0.681 \pm 0.037$ & $(78.9)^{*}$ & \\
\hline & 8 & $0.616 \pm 0.054$ & $(71.4)^{*}$ & \\
\hline & 16 & $0.467 \pm 0.032$ & $(54.1)^{* *}$ & \\
\hline & 32 & $0.356 \pm 0.013$ & $(41.3)^{* * *}$ & \\
\hline MAO-B (clorgyline-treated) & & & & 7.0 \\
\hline Control+clorgyline & & $1.155 \pm 0.059$ & $(100.0)$ & \\
\hline \multirow[t]{4}{*}{ Piperine } & 2 & $0.947 \pm 0.048$ & $(82.0)$ & \\
\hline & 5 & $0.826 \pm 0.036$ & $(71.5)^{*}$ & \\
\hline & 10 & $0.455 \pm 0.025$ & $(39.4)^{* * *}$ & \\
\hline & 20 & $0.253 \pm 0.017$ & $(21.9)^{* * *}$ & \\
\hline
\end{tabular}

The activities of MAO-A and MAO-B in mouse brain were measured in the presence of $1 \mu \mathrm{M} l$-deprenyl or clorgyline, respectively. The data represent the mean \pm S.E.M. of three independent experiments performed in triplicate. Significantly different from the control value: $* p<0.05 ; * * p<0.01 ; * * * p<0.001$ (Student's $t$-test).

piperine showed a slightly more potent inhibitory effect against MAO-B $\left(\mathrm{IC}_{50}: 7.0 \mu \mathrm{M}\right)$ than MAO-A $\left(\mathrm{IC}_{50}: 20.9 \mu \mathrm{M}\right)$ (Table 2). To understand the inhibition mode, a kinetic study was performed on MAO-A and MAO-B at different concentrations of the substrate in the absence or presence of piperine. Kinetic analyses by a Lineweaver-Burk reciprocal plot clearly indicated that the inhibition mode of MAO-A and MAO-B with piperine was competitive with the $K_{\mathrm{i}}$ values of $19.0 \pm 0.9 \mu \mathrm{M}$ and $3.19 \pm 0.5 \mu \mathrm{M}$, respectively $(n=3)$ (Fig. 2).

A recent paper reported that piperine showed a slightly more potent inhibitory effect against MAO-A $\left(\mathrm{IC}_{50}: 49.3 \mu \mathrm{M}\right)$ than MAO-B $\left(\mathrm{IC}_{50}: 91.3 \mu \mathrm{M}\right)$. Kinetic analyses by a Lineweaver-Burk plot indicated that the piperine inhibition of MAO-A and MAO-B was of mixed and competitive types, respectively. ${ }^{17)}$ The discrepancy in the inhibitory effects of piperine may be due to the differences in experimental conditions and in the substrate of the MAO enzyme.

To confirm the reversibility of piperine, the MAO-A and MAO-B from mouse brain mitochondrial fraction were incubated with piperine for $30 \mathrm{~min}$ at $37^{\circ} \mathrm{C}$, then the reaction mixtures were dialyzed against $10 \mathrm{~mm}$ potassium phosphate buffer, $\mathrm{pH} 7.4$ at $4{ }^{\circ} \mathrm{C}$ overnight. After dialysis, the MAO-A and MAO-B activities were recovered to 97.2 and $96.2 \%$ relative to the control, and were also inhibited by piperine (20, $7 \mu \mathrm{M})$ as summarized in Table 3 . These results suggest that piperine is a reversible inhibitor for MAO-A and MAO-B, respectively.

Reversible inhibitors of monoamine oxidase have been introduced for the treatment of depression, because the irreversibility as well as the non-specificity of MAO inhibitors is thought to be associated with their unfavorable side effect profiles. ${ }^{18)}$

Regulation of MAO-A activity has been thought to be an effective approach for the treatment of depression and anxiety, while regulation of MAO-B appears to be helpful in the prevention and adjunct treatment of Parkinson's disease. ${ }^{1,5}$ Although piperine showed a slightly more potent inhibitory effect on MAO-B than MAO-A, in vivo CNS depressant activity was also reported. ${ }^{12,13)}$ To confirm the antidepressant effect of piperine, we evaluated in vivo tail suspension tests in mice. The tail suspension and forced swimming tests are behavioral tests in rodents that predict the clinical efficacy of
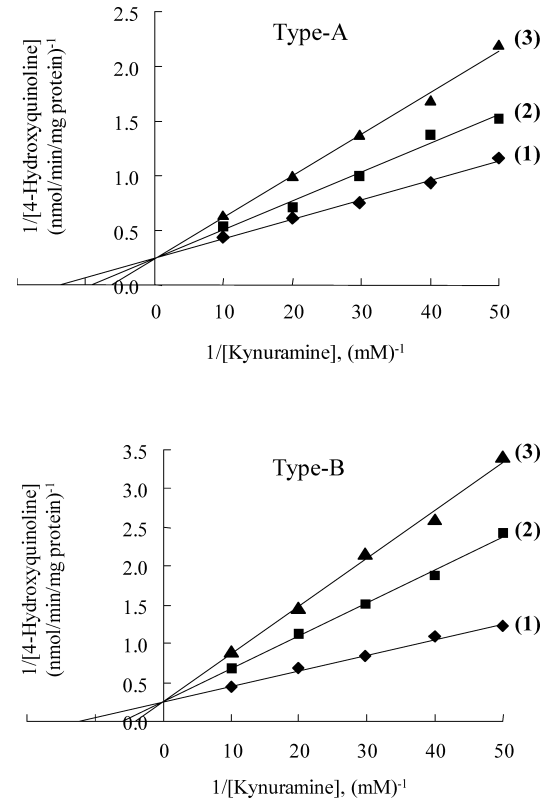

Fig. 2. Competitive Inhibition of MAO-A and MAO-B by Piperine Added in the Enzyme Reaction Mixture

The reciprocals of MAO-A and MAO-B activities were plotted against the reciprocals of substrate concentration. Piperine concentrations ( $\mu \mathrm{M})$ : MAO-A (1) $0 \mu \mathrm{M}$, (2) $9 \mu \mathrm{M}$, (3) $21 \mu \mathrm{m}$; MAO-B (1) $0 \mu \mathrm{M}$, (2) $3.5 \mu \mathrm{m}$, (3) $7 \mu \mathrm{m}$.

Table 3. Effects of Dialysis on the Inhibition of MAO-A and MAO-B by Piperine

\begin{tabular}{lcc}
\hline \hline Enzymes & \multicolumn{2}{c}{$\begin{array}{c}\text { MAO activity (\% of control) } \\
(\mathrm{nmol} / \mathrm{min} / \mathrm{mg} \text { protein })\end{array}$} \\
\hline Before dialysis & & $(100.0)$ \\
MAO-A (deprenyl-treated) & $0.529 \pm 0.035$ & $(38.2)^{* * *}$ \\
Piperine 20 $\mu \mathrm{M}$ & $0.202 \pm 0.012$ & $(100.0)$ \\
MAO-B (clorgyline-treated) & $1.326 \pm 0.097$ & $(49.0)^{* *}$ \\
Piperine 7 $\mu \mathrm{M}$ & $0.650 \pm 0.046$ & $(97.2)$ \\
After dialysis & & $(39.2)^{* * *}$ \\
Dialysate (MAO-A) & $0.514 \pm 0.040$ & $(96.2)$ \\
Piperine 20 $\mu \mathrm{M}$ & $0.207 \pm 0.011$ & $(31.6)^{* * *}$ \\
Dialysate (MAO-B) & $1.276 \pm 0.088$ & \\
Piperine 7 $\mu \mathrm{M}$ & $0.419 \pm 0.023$ & \\
\hline
\end{tabular}

Results represent the mean \pm S.E.M. of three independent experiments performed in triplicate. Significantly different from the control value: $* * p<0.01 ; * * * p<0.001$ (Student's $t$-test). 


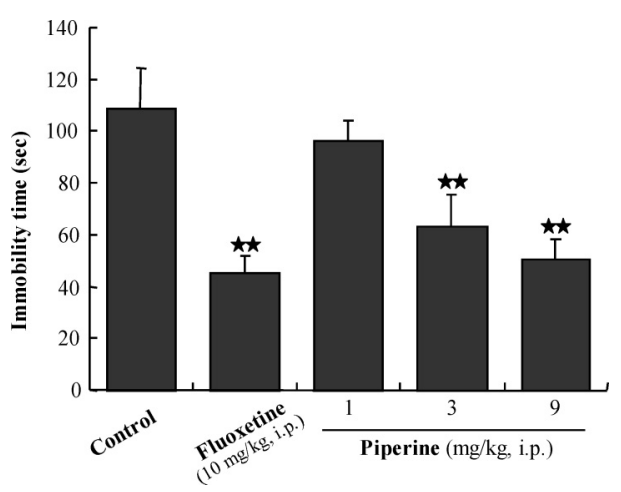

Fig. 3. Effect of Piperine on Immobility Time in the Tail Suspension Test in Mice

Piperine and fluoxetine (the positive control) were given intraperitoneally (i.p.) 60 min before the test. Each value represents the mean \pm S.E.M. $(n=8)$. Significance of differences between groups was evaluated with a one-way analysis of variance (ANOVA): $* * p<0.01$ versus control.

many types of antidepressant treatments. ${ }^{19,20)}$ As shown in Fig. 3, piperine decreased the immobility time in a dose-dependent manner, and this effect was statistically significant at doses of 3 and $9 \mathrm{mg} / \mathrm{kg}$ (i.p.). This activity was comparable to that of fluoxetine, a reference antidepressant agent. Fluoxetine $(10 \mathrm{mg} / \mathrm{kg}$, i.p.) reduced the immobility time by $58 \%$ in these tests.

In order to prove that the reduction of immobility time in the tail suspension test does not seem to be associated with an unspecific increase in locomotor activity, ${ }^{21,22)}$ we investigated the spontaneous motor activity induced by piperine in a separate experiment. In this study, piperine and fluoxetine, at doses which produced an antidepressant-like effect, did not significantly change the motor activity in mice when tested in an open-field test (number of crossings, control: 102 \pm 9 ; $3 \mathrm{mg} / \mathrm{kg}$ of piperine: $98 \pm 7 ; 9 \mathrm{mg} / \mathrm{kg}$ of piperine: $91 \pm 5$; $10 \mathrm{mg} / \mathrm{kg}$ of fluoxetine: $89 \pm 4 ; n=8$ per group). This result demonstrated that the antidepressant-like effect of piperine in the tail suspension test was not based on any stimulation of locomotor activity.

As previously noted, inhibitors of MAO activity have been believed to successfully treat depression and Parkinson's disease. It is suggested that MAO-A acts preferentially on serotonin and norepinephrine, while MAO-B acts preferentially on dopamine. Dopamine is a substrate for MAO-B and is known to play a significant antidepressant role. ${ }^{23)}$ Thus, the antidepressant-like effect of piperine may be mediated through the enhancement of serotonergic and norepinephrinegic neurotransmission, as well as by dopaminergic neurotransmission. However, additional study aiming at understanding the mode of action remains to be elucidated.

In conclusion, we have shown that piperine, an active piperidine alklaoid from $P$. longum, reversibly inhibited mouse brain MAO-A and MAO-B activities. In addition, piperine has in vivo antidepressant-like activity against the tail suspension test. Although the precise mechanism involved in the observed antidepressant activity is not yet clear, piperine has potential therapeutic value for the management of depressive disorders and is considered a good candidate for further evaluation.

\section{Experimental}

Plant Material The dried fruits of $P$. longum were purchased from an herbal drug store at Cheongju, Korea, in 2001 and identified by Prof. K. S. Lee, a plant taxonomist at Chungbuk National University. The voucher specimens (CBNU 01096) were deposited at the College of Pharmacy, Chungbuk National University.

General Experimental Procedures Melting point, UV, IR and MS were obtained as described previously. ${ }^{24)}{ }^{1} \mathrm{H}$ - and ${ }^{13} \mathrm{C}$-NMR spectra were obtained on a Bruker DRX-300 spectrometer with tetramethylsilane (TMS) as an internal standard. Open column chromatography was performed on silica gel 60 (230 - 400 mesh, Fisher Scientific). The fluorescence intensities were measured on a Perkin Elmer LS50B fluorescence spectrophotometer. Kynuramine, 4-hydroxyquinoline, $l$-depreyl, clorgyline, and iproniazid were purchased from Sigma Chemical Co. (St. Louis, MO, U.S.A.).

Extraction and Activity-Guided Isolation The dried fruits of $P$. longum $(3 \mathrm{~kg}$ ) were extracted with $95 \% \mathrm{EtOH}$ four times at room temperature to afford a dark-brown residue $(450 \mathrm{~g}, 91.0 \% \mathrm{MAO}$ inhibitory activity at the concentration of $250 \mu \mathrm{g} / \mathrm{ml}$ ). The ethanol extract was suspended in water, and then partitioned in turn with hexane, $\mathrm{CH}_{2} \mathrm{Cl}_{2}, \mathrm{EtOAc}, \mathrm{BuOH}$, and water. When evaluated at $200 \mu \mathrm{g} / \mathrm{ml}$, the MAO inhibitory activities for these five extracts were $82.8,91.0,29.6,26.6$, and $18.6 \%$, respectively. The most active $\mathrm{CH}_{2} \mathrm{Cl}_{2}$ extract $(120 \mathrm{~g})$ was chromatographed over silica gel column with a gradient of $\mathrm{MeOH}$ in $\mathrm{CH}_{2} \mathrm{Cl}_{2}(1,2,5,10,20,50,100 \%, 11$ each) as the solvent system, and afforded seven combined fractions $(\mathrm{C} 1-\mathrm{C} 7)$. When evaluated at $100 \mu \mathrm{g} / \mathrm{ml}$, the MAO inhibitory activities for these seven extracts were $93.8,99.8,79.7,41.6,33.3,3.2$, and $8.0 \%$, respectively. Piperine (450 mg, $\mathrm{C}_{17} \mathrm{H}_{19} \mathrm{NO}_{3}, \mathrm{mp} 130-133^{\circ} \mathrm{C}$ ) was isolated from the most active fraction $(\mathrm{C} 2)$ by recrystallization in the mixture of $\mathrm{CH}_{2} \mathrm{Cl}_{2}$ and $\mathrm{MeOH}$.

MAO Preparation and Assay for MAO Activity A crude mitochondrial fraction from mouse brain was isolated by the method of Naoi et al. ${ }^{25)}$ with minor modification. ${ }^{8)}$ MAO activity was measured fluorometrically using kynuramine as a substrate according to the method of $\mathrm{Kraml}^{26)}$ with slight modification. ${ }^{24)}$ The values of the Michaelis constant $\left(K_{\mathrm{m}}\right)$ and the maximum velocity $\left(V_{\max }\right)$ were calculated from a Lineweaver-Burk plot using various concentrations of kynuramine. In order to verify the reversibility of inhibition, MAO from mouse brain mitochondrial fraction was incubated with piperine for $30 \mathrm{~min}$ at $37^{\circ} \mathrm{C}$, and then the reaction mixture was dialyzed against $10 \mathrm{~mm}$ potassium phosphate buffer $\mathrm{pH} 7.4$ at $4{ }^{\circ} \mathrm{C}$ overnight. MAO activity in the dialysate was measured using $100 \mu \mathrm{M}$ of kynuramine in the absence of and presence of piperine. Undialyzed portions of each mixture were maintained at $4{ }^{\circ} \mathrm{C}$ over the same time period. Both the dialyzed and undialyzed mixtures were assayed for MAO activity at the same time. ${ }^{24)}$

Animals ICR male mice weighing 20-23g were purchased from Samyook Animal Center (Soowon, Korea) and maintained in accordance with the guidelines for animal care and use of laboratory animals, Chungbuk National University, Korea. They were allowed at least 1 week to adapt to their environment before use in this experiment. They were housed at $25 \pm 2{ }^{\circ} \mathrm{C}$ with a regular $12 \mathrm{~h}$ light $/ 12 \mathrm{~h}$ dark cycle, and given standard chow and water ad libitum for the duration of the study.

In Vivo Tail Suspension Test The animals were randomized into five groups containing eight animals per group in each experiment. Group 1 was administered normal saline $(0.9 \% \mathrm{NaCl})$. Animals in groups 2, 3 and 4 were treated with $1,3,9 \mathrm{mg} / \mathrm{kg}$ of piperine, respectively. Group 4 was administered fluoxetine at the dose of $10 \mathrm{mg} / \mathrm{kg}$. All drugs were given intraperitoneally (i.p.) $60 \mathrm{~min}$ prior to the test in mice. The tail suspension test is based on the method of Steru et al. ${ }^{20)}$ Briefly, a mouse was individually suspended by the tail with a clamp ( $1 \mathrm{~cm}$ distance from the end) for $6 \mathrm{~min}$ in a box $(25 \times 25 \times 30 \mathrm{~cm})$ with the head $5 \mathrm{~cm}$ to the bottom. Testing was carried out in a darkened room with minimal background noise. The duration of immobility was observed during the final 4 min interval of the test.

Measurement of Spontaneous Motor Activity The spontaneous motor activity of mice was carried out in an open-field test as described previously. ${ }^{27)}$ The open-field apparatus consisted of a circular base $(80 \mathrm{~cm}$ in diameter, $20 \mathrm{~cm}$ high wall) with three concentric circles of 14,28 , and $42 \mathrm{~cm}$ radius, divided into 36 units without walls. A mouse was placed individually into the center of the arena and allowed to explore freely. Piperine (3, $9 \mathrm{mg} / \mathrm{kg})$, fluoxetine $(10 \mathrm{mg} / \mathrm{kg})$ and normal saline were injected intraperitoneally $60 \mathrm{~min}$ before the measurement of locomotor activity. The numbers of squares crossed with all paws (crossings) was counted in a 5 min session.

Acknowledgements This work was supported by grant No. R05-2001000-00664-0 from the Basic Research Program of the Korea Science \& Engineering Foundation. We are grateful to the Korea Basic Science Institute for ${ }^{1} \mathrm{H}$ - and ${ }^{13} \mathrm{C}$-NMR spectral measurements. 


\section{References}

1) Shih J. C., Chen K., Ridd M. J., Annu. Rev. Neurosci., 22, 197-217 (1999).

2) Bach A. W., Lan N. C., Johnson D. L., Abell C. W., Bembenek M. E., Kwan S. W., Seeburg P. H., Shih J. C., Proc. Natl. Acad. Sci. U.S.A., 85, 4934-4938 (1988).

3) Abell C. W., Kwan S. W., Prog. Nucl. Acids Res. Mol. Biol., 65, 129$156(2001)$.

4) Kalgutkar A. S., Castagnoli N. Jr., Med. Res. Rev., 15, 325-388 (1995).

5) Jegham S., George P., Exp. Opin. Ther. Patents, 8, 1143-1150 (1998).

6) Gnerre C., Catto M., Leonetti F., Weber P., Carrupt P. A., Altomare C., Carotti A., Testa B., J. Med. Chem., 43, 4747-4758 (2000).

7) Suzuki O., Katsumata Y., Oya M., Chari V. M., Vermes B., Wagner H., Hostettmann K., Planta Med., 42, 17-21 (1981).

8) Ro J. S., Lee S. S., Lee K. S., Lee M. K., Life Sci., 70, 639-645 (2001).

9) Kong L. D., Cheng C. H., Tan R. X., Planta Med., 67, 74-76 (2001).

10) Parmar V. S., Jain S. C., Bisht K. S., Jain R., Taneja P., Jha A., Tyagi O. M., Prasad A. K., Wengel J., Olsen C. E., Boll P. M., Phytochemistry, 46, 597-673 (1997).

11) Jung B. S., Shin M. K., "Encyclopedia of Illustrated Korean Natural Drugs," Young Lim Sa, Seoul, 1989, pp. 818 - 819.

12) Lee E. B., Shin K. H., Woo W. S., Arch. Pharm. Res., 7, 127-132 (1984).

13) Woo W. S., Lee E. B., Shin K. H., Arch. Pharm. Res., 2, 121-125
(1979).

14) Pei Y. Q., Epilepsia, 24, 177-182 (1983).

15) Tabuneng W., Bando H., Amiya T., Chem. Pharm. Bull., 31, 35623565 (1983).

16) De Araujo-Junior J. X., Da-Cunha E. V. L., De O. Chaves M. C., Gray A. I., Phytochemistry, 44, 559-561 (1997).

17) Kong L. D., Cheng C. H. K., Tan R. X., J. Ethnopharmacol., 91, 351355 (2004).

18) Da Prada M., Kettler R., Keller H. H., Cesura A. M., Richards J. G., Saura Marti J., Muggli-Maniglio D., Wyss P. C., Kyburz E., Imhof R., J. Neural. Transm. Suppl., 29, 279-292 (1990).

19) Porsolt R. D., Le Pichon M., Jalfre M., Nature (London), 266, 730 732 (1977).

20) Steru L., Chermat R., Thierry B., Simon P., Psychopharmacology, 85, 367-370 (1985).

21) Porsolt R. D., Anton G., Blavet N., Jalfre M., Eur. J. Pharmacol., 47, 379-391 (1978).

22) Willner P., Psychopharmacology, 83, 1-16 (1984)

23) Kapur S., Mann J. J., Biol. Psychiatry, 32, 1-17 (1992).

24) Lee M. K., Hwang B. Y., Lee S. A., Oh G. J., Choi W. H., Hong S. S., Lee K. S., Ro J. S., Chem. Pharm. Bull., 51, 409-411 (2003).

25) Naoi M., Nagatsu T., J. Neurochem., 46, 655-657 (1986).

26) Kraml M., Biochem. Pharmacol., 14, 1684-1686 (1965).

27) Kulkarni S. K., Dandiya P. C., Psychopharmacologia, 33, 333-338 (1973). 